\title{
Efisiensi Ekonomi Usahatani Padi Lahan Kering di Kabupaten Lampung Selatan
}

\author{
Muhammad Fauzan ${ }^{\mathrm{a}}$ \\ ${ }^{a}$ Program Studi Agribisnis, Fakultas Pertanian, Universitas Muhammadiyah Yogyakarta, Indonesia, email: muhammad.fauzan@umy.ac.id
}

\section{Article Info}

Article history:

Received 2 April 2020

Received in revised form 13 April 2020

Accepted 5 Mei 2020

DOI:

https://doi.org/10.32938/ag.v5i3.1018

Keywords:

Efisiensi Ekonomi

Faktor Produksi

Padi Lahan Kering

\section{Abstrak}

Pemanfaatan lahan kering untuk usahatani padi merupakan salah satu upaya untuk meningkatkan produksi padi nasional dalam rangka memenuhi kebutuhan pangan. Untuk mencapai produktivitas yang tinggi, sistem usahatani padi lahan kering harus dilakukan secara efisien sehingga perlu keterampilan ekstra dari setiap individu petani. Penelitian ini bertujuan untuk untuk menganalisis faktor-faktor yang mempengaruhi produksi dan tingkat efisiensi ekonomi usahatani padi lahan kering di Kabupaten Lampung Selatan. Pengumpulan data dilakukan dengan metode survey pada 60 petani responden. Fungsi produksi stochastic frontier digunakan dalam penelitian ini untuk analisis data. Hasil penelitian menunjukkan bahwa faktor-faktor yang mempengaruhi produksi padi lahan kering di Kabupaten Lampung Selatan adalah luas lahan, benih, pupuk N, pupuk P, pestisida padat, tenaga kerja, dan jenis benih. Rata-rata capaian efisiensi teknis, alokatif, dan ekonomi usahatani padi lahan kering di Kabupaten Lampung Selatan adalah sebesar 0,869; 0,957; dan 0,829. Untuk mencapai tingkat efisien secara ekonomi, petani perlu meningkatkan capaian efisiensi teknis dan alokatifnya.

\section{Pendahuluan}

Program swasembada pangan pada komoditas strategis seperti padi telah dicanangkan oleh pemerintah dalam upaya menekan impor untuk memenuhi kebutuhan pangan nasional yang semakin meningkat setiap tahun. Salah satu upaya yang terus dilakukan adalah perluasan areal tanam dengan memanfaatkan lahan kering yang sejauh ini belum digunakan secara optimal untuk usahatani padi. Hal ini dilakukan karena lahan sawah intensif yang semakin berkurang akibat terjadinya degradasi lahan dan air, kerusakan lingkungan, perubahan iklim (Mulyani et al. 2011), dan konversi lahan pertanian untuk non pertanian. Akibatnya, produksi pangan dari lahan sawah intensif semakin berkurang (Irawan \& Adiningsih, 2015).

Menurut Badan Pusat Statistik (2004), lahan kering dikelompokan menjadi pekarangan, kebun/tegalan/huma/ladang, padang rumput, lahan sementara yang tidak diusahakan, dan perkebunan. Lahan kering adalah salah satu sumber daya yang punya potensi sangat besar bagi keberlanjutan pembangunan pertanian nasional, khususnya pemanfaatan ladang untuk usahatani padi. Pengembangan lahan kering berupa ladang untuk usahatani padi saat ini dan juga masa mendatang adalah pilihan strategis untuk mendukung tercapainya program ketahanan pangan nasional.

Kabupaten Lampung Selatan adalah sentra produksi padi lahan kering di Provinsi Lampung (Indah et al. 2015). Umumnya padi diusahakan pada areal sawah tadah hujan yang hanya ditanam pada musim hujan. Pertumbuhan dan hasil produksinya sangat bergantung pada tersedianya air hujan sebagai sumber pengairan. Kelembaban tanahnya pun sangat dipengaruhi oleh curah hujan. Permasalahan yang dihadapi oleh petani padi lahan kering di Kabupaten Lampung Selatan cukup banyak, terutama pada alokasi faktor-faktor produksi, ketersediaan air, dan kondisi kesuburan tanah yang rendah. Benih yang ditanam oleh petani umumnya menggunakan benih turunan dari tanaman padi musim sebelumnya. Benih padi tersebut disimpan untuk dijadikan benih pada tahun tanam selanjutnya. Penggunaan faktor produksi pupuk dan pestisida oleh petani semata-mata dialokasikan berdasarkan kebiasaan petani yang telah berjalan turun-temurun, tanpa memperhatikan aspek agronomis, ekonomi, dan lingkungan.

Sistem usahatani padi lahan kering harus dilakukan secara intensif untuk mencapai produktivitas yang tinggi. Hal ini tentu memerlukan keterampilan yang ekstra dari setiap petani. Mengkaji tentang produktivitas suatu unit usahatani sebenarnya ialah mengkaji tentang efisiensi. (Kay et al. 2008). Hal ini dapa dimengerti karena ukuran produktivitas mempengaruhi tingkat efisiensi teknis, alokatif, dan ekonomi yang pada akhirnya menunjukkan seberapa besar produksi maksimum dapat dihasilkan dari tiap-tiap faktor produksi yang tersedia dan bisa diakses oleh petani. Kemampuan manajerial petani dalam teknologi budidaya serta kapabilitasnya dalam mengolah berbagai informasi yang relevan akan sangat mempengaruhi capaian tingkat efisiensi sehingga setiap keputusan dapat diambil secara tepat.

Petani padi lahan kering harus mampu mengalokasikan setiap input yang dipakai sedemikian rupa sehingga usahataninya bisa efisien dan mendapatkan keuntungan yang cukup untuk penghidupan keluarganya serta mengembangkan usahataninya. Dari uraian tersebut, penelitian ini memiliki tujuan untuk menganalisis faktor-faktor yang berpengaruh terhadap produksi padi lahan kering dan menganalisis tingkat efisiensi ekonomi usahatani padi lahan kering di Kabupaten Lampung Selatan.

\section{Metode}

Penelitian ini dilaksanakan di Kecamatan Sidomulyo yang merupakan sentra produksi padi di Kabupaten Lampung Selatan (Indah et al. 2015). Metode simple random sampling digunakan untuk mengambil responden sebanyak 60 orang anggota Gapoktan Karya Tani yang merupakan wadah kelompok tani paling aktif dalam pengembangan usahatani padi lahan kering di Kecamatan Sidomulyo Kabupaten Lampung Selatan. Fungsi produksi stochastic frontier digunakan untuk menganalisis faktor-faktor yang berpengaruh terhadap produksi padi lahan kering dan tingkat efisiensi teknisnya, sebagai berikut : $\ln Y=\beta_{0}+\beta_{1} \ln L L_{1}+\beta_{2} \ln B N H_{2}+\beta_{3} \ln P N_{3}+\beta_{4} \ln P P_{4}+\beta_{5} \ln P K_{5}+$ $\beta_{6} \ln P C_{6}+\beta_{7} \ln P D_{7}+\beta_{8} \ln T K_{8}+\beta_{9} \ln D+\left(v_{i}-u_{i}\right)$

\section{Keterangan :}

$\mathrm{Y} \quad=$ Produksi padi $(\mathrm{kg})$

$\mathrm{LL}_{1}=$ Luas lahan (ha)

$\mathrm{BNH}_{2}=$ Benih $(\mathrm{kg})$

$\mathrm{PN}_{3}=$ Pupuk N (kg)

$\mathrm{PP}_{4}=$ Pupuk P $(\mathrm{kg})$

$\mathrm{PK}_{5} \quad=$ Pupuk K $(\mathrm{kg})$

$\mathrm{PC}_{6}=$ Perstisida cair (liter)

$\mathrm{PD}_{7}=$ Pesrtisida padat $(\mathrm{kg})$

$\mathrm{TK}_{8}=$ Tenaga kerja $(\mathrm{HKO})$

$\mathrm{D}=$ Dummy jenis benih, dimana $\mathrm{D}_{0}$ : benih turunan, $\mathrm{D}_{1}$ : benih baru atau beli

$\beta_{0} \quad=$ Intersep

$\beta_{\mathrm{i}} \quad=$ Koefisien Regresi

$\mathrm{V}_{\mathrm{i}} \quad=$ Kesalahan acak model

$\mathrm{u}_{\mathrm{i}} \quad=$ Efek inefisiensi teknis

Penentuan faktor-faktor sumber inefisiensi teknis dengan persamaan :

$u_{i}=\delta_{0}+\delta_{1} \ln Z_{1}+\delta_{2} \ln Z_{2}+\delta_{3} \ln Z_{3}+\delta_{4} D+\delta_{5} \ln Z_{4}$

Keterangan :

$\mathrm{Z}_{1} \quad=$ Umur (tahun)

$\mathrm{Z}_{2} \quad=$ Pengalaman (tahun)

$\mathrm{Z}_{3} \quad=$ Pendidikan formal (tahun)

$\mathrm{D}=$ Dummy kepemilikan lahan, dimana $\mathrm{D}_{0}:$ milik sendiri, $\mathrm{D}_{1}$ : sewa dan sakap

$\mathrm{Z}_{4} \quad=$ Frekuensi mengikuti penyuluhan (kali)

Program FRONTIER 4.1 digunakan untuk menduga parameter dari persamaan tersebut dengan pendekatan Maximum Likelihood Estimation (MLE) Output program ini akan menghasilkan nilai efisiensi teknis usahatani padi lahan kering, dengan rumus :

$T E_{i}=\frac{Y}{Y^{*}}=\frac{E\left(Y_{i} \mid U_{i}, X_{i}\right)}{E\left(Y_{i} \mid U_{i}=0, X_{i}\right)}=E\left[\exp \left(-U_{i}\right) / \varepsilon_{i}\right]$

Dimana :

$\mathrm{TE}_{\mathrm{i}}=$ Efisiensi teknis responden petani padi ke-i

$\mathrm{Y}=$ Produksi aktual dari pengamatan

$\mathrm{Y}^{*} \quad=$ Dugaan produksi frontier

Nilai efisiensi teknis yang dapat dicapai oleh petani padi lahan kering berada diantara 0 sampai dengan 1 . Nilai yang mendekati 1 menunjukkan usahatani padi lahan kering telah mencapai tingkat yang efisien (Nalle, 2016) Sebaliknya nilai mendekati 0 menunjukkan petani padi lahan kering inefisien secara teknis. Kombinasi diantara efisiensi teknis dan alokatif akan menghasilkan efisiensi ekonomi. Tingkat efisiensi ekonomi antara satu petani dengan petani lainnya akan berbeda tergantung dari capaian efisiensi teknis atau efisiensi alokatif atau keduanya. Jondrow et al. (1982) mengemukakan bahwa nilai efisiensi ekonomi merupakan rasio antara total biaya minimal $\left(\mathrm{C}^{*}\right)$ dengan total biaya aktualnya (C), sebagaimana rumus berikut :

Dimana :

$$
E E=\frac{C^{*}}{C}=\frac{E\left(C_{i} \mid U_{i}=0, Y_{i} P_{i}\right)}{E\left(C_{i} \mid U_{i}, Y_{i}, X_{i}\right)}=E\left[\exp \left(-U_{i}\right) / \varepsilon_{i}\right]
$$

$\mathrm{EE} \quad=$ Efisiensi Ekonomi

$\mathrm{C}^{*} \quad=$ Total Biaya Minimal

$\mathrm{C} \quad=$ Total Biaya Aktual 
Model fungsi biaya stochastic frontier tipe Cobb-Douglas digunakan untuk menganalisis efisiensi ekonomi usahatani padi lahan kering sebagai berikut :

$\ln C=\beta_{0}+\beta_{1} \ln Y+\beta_{2} \ln P R_{2}+\beta_{3} \ln P R_{3}+\beta_{4} \ln P R_{4}+\beta_{5} \ln P R_{5}+$ $\beta_{6} \ln P R_{6}+\beta_{7} \ln P R_{7}+\beta_{8} \ln P R_{8}+\beta_{9} D+\left(v_{i}-u_{i}\right)$

Dimana :

$\mathrm{C}=$ Total biaya produksi $(\mathrm{Rp})$

$\mathrm{Y}=$ Produksi padi lahan kering $(\mathrm{kg})$

$\mathrm{PR}_{2}=$ Harga benih $(\mathrm{Rp} / \mathrm{kg})$

$\mathrm{PR}_{3}=$ Harga pupuk $\mathrm{N}(\mathrm{Rp} / \mathrm{kg})$

$\mathrm{PR}_{4}=$ Harga pupuk $\mathrm{P}(\mathrm{Rp} / \mathrm{kg})$

$\mathrm{PR}_{5}=$ Harga pupuk $\mathrm{K}(\mathrm{Rp} / \mathrm{kg})$

$\mathrm{PR}_{6}=$ Harga pestisida cair $(\mathrm{Rp} /$ liter $)$

$\mathrm{PR}_{7}=$ Harga pestisida padat $(\mathrm{Rp} / \mathrm{kg})$

$\mathrm{PR}_{8}=$ Upah tenaga kerja $(\mathrm{Rp} / \mathrm{HKO})$

$\mathrm{D}=$ Dummy jenis benih, dimana $\mathrm{D}_{0}$ : benih turunan, $\mathrm{D}_{1}$ : benih baru atau bel

$\beta_{0}=$ Intersep

$\beta_{\mathrm{i}}=$ Koefisien Regresi

$\mathrm{v}_{\mathrm{i}}=$ Kesalahan acak mode

$\mathrm{u}_{\mathrm{i}}=$ Efek inefisiensi teknis

Penentuan faktor-faktor sumber inefisiensi dengan persamaan :

$u_{i}=\delta_{0}+\delta_{1} \ln Z_{1}+\delta_{2} \ln Z_{2}+\delta_{3} \ln Z_{3}+\delta_{4} D+\delta_{5} \ln Z_{4}$

Keterangan :

$Z_{1}=$ Umur (tahun)

$Z_{2}=$ Pengalaman (tahun)

$\mathrm{Z}_{3}=$ Pendidikan formal (tahun)

$\mathrm{D}=$ Dummy kepemilikan lahan, dimana $\mathrm{D}_{0}:$ milik sendiri, $\mathrm{D}_{1}:$ sewa dan sakap

$\mathrm{Z}_{4}=$ Frekuensi mengikuti penyuluhan (kali)

Sama seperti pada analisis sebelumnya, Program FRONTIER 4.1 digunakan untuk menduga parameter dari persamaan tersebut. Sebagaimana pendapat Fauzan (2016), perhitungan dari program komputasi tersebut ialah mengukur efisiensi biaya. Untuk mendapatkan nilai efisiensi ekonomi dihitung dengan rumus :

$$
E E=\frac{1}{\text { Cost Efficency }(C E)}
$$

Karena perkalian dari efisiensi teknis dan efisiensi alokatif adalah efisiensi ekonomi, maka besarnya nilai efisiensi alokatif dapat diperoleh dengan rumus :

$$
E A=\frac{E E}{E T}
$$

Dimana nilai efisiensi alokatif berada diantara 0 sampai dengan 1 .

\section{Hasil dan Pembahasan}

\subsection{Faktor-Faktor yang Mempengaruhi Produksi Padi Lahan Kering}

Hasil estimasi fungsi produksi stochastic frontier usahatani padi lahan kering dengan metode Maximum Likelihood Estimation ditunjukkan pada Tabel 1 .

Tabel 1. Hasil Estimasi Fungsi Produksi Stochastic Frontier Usahatani Padi Lahan Kering

\begin{tabular}{lcrrc}
\hline \multicolumn{1}{c}{ Variabel } & Parameter & Koefisien & \multicolumn{1}{c}{ Standar error } & \multicolumn{1}{c}{ hitung } \\
\hline Konstanta & $\alpha$ & 0,603 & 0,949 & $6,356^{* * *}$ \\
Luas lahan & $\beta_{1}$ & 0,554 & 0,177 & $3,118^{* * *}$ \\
Benih & $\beta_{2}$ & 0,218 & 0,111 & $1,958^{*}$ \\
Pupuk N & $\beta_{3}$ & $-0,182$ & 0,101 & $-1,790^{*}$ \\
Pupuk P & $\beta_{4}$ & 0,980 & 0,527 & $1,859^{*}$ \\
Pupuk K & $\beta_{5}$ & 0,391 & 0,387 & $1,010^{\text {ns }}$ \\
Pestisida cair & $\beta_{6}$ & $-0,687$ & 0,489 & $-1,403^{\text {ns }}$ \\
Pestisida padat & $\beta_{7}$ & $-0,103$ & 0,321 & $-3,225^{* * *}$ \\
Tenaga kerja & $\beta_{8}$ & 0,324 & 0,152 & $2,131^{* *}$ \\
Dummy benih & $\mathrm{D}$ & 0,292 & 0,752 & $3,892^{* * *}$ \\
Sigma-squared & & 0,489 & 0,137 & $3,558^{* * *}$ \\
Gamma & & 0,905 & 0,413 & $2,192^{* *}$ \\
\hline
\end{tabular}

\begin{tabular}{|c|c|c|}
\hline Keterangan & $* * *$ & : signifikan untuk $\alpha=1 \%$ \\
\hline & $* *$ & : signifikan untuk $\alpha=5 \%$ \\
\hline & * & : signifikan untuk $\alpha=10 \%$ \\
\hline & ns & : non signifikan \\
\hline
\end{tabular}

Sumber : Data primer, diolah, 2019

Nilai sigma-squared 0,489 signifikan pada $\alpha$ sebesar $1 \%$ menunjukkan bahwa keragaman produksi padi lahan kering di Kabupeten Lampung Selatan yang berasal dari efek inefisiensi dan efek eksternal memiliki variasi yang nyata. Nilai gamma 0,905 memiliki arti bahwa perbedaan efisiensi teknis menjadi sebab terjadinya $90,5 \%$ variasi produksi padi lahan kering di Kabupaten Lampung Selatan. Faktor eksternal seperti pengaruh hama dan penyakit tanaman, perubahan iklim, dan kesalahan dalam pemodelan hanya berpengaruh sebesar 9,5\%. Hasil ini menunjukkan faktor inefisiensi teknis berpengaruh nyata terhadap variasi produksi padi yang terjadi di tingkat petani.

Faktor produksi luas lahan, benih, pupuk P, pupuk K, tenaga kerja, dan jenis benih yang bertanda positif menunjukkan produksi padi lahan kering akan bertambah seiring penambahan masing-masing faktor produksi tersebut. Pupuk $\mathrm{N}$ bertanda negatif memiliki arti bahwa penambahannya justru akan menurunkan produksi. Kondisi ini terjadi karena penggunaan pupuk $\mathrm{N}$ yang telah berlebih. Koefisien faktor produksi pestisida cair dan pestisida padat yang bertanda negatif menunjukkan bahwa penambahan pestisida belum tentu dapat meningkatkan produksi padi, sebaliknya justru akan menurunkan produksinya. Penggunaan pestisida secara berlebihan akan menjadi sebab tanaman tidak akan bisa tumbuh dan berkembang dengan optimal.

Hasil uji parsial menunjukkan faktor produksi luas lahan, benih, pupuk $\mathrm{N}$, pupuk $\mathrm{P}$, pestisida padat, tenaga kerja, dan jenis benih nyata berpengaruh pada produksi padi lahan kering. Luas lahan merupakan variabel yang sangat responsif karena memiliki koefisien yang cukup besar. Hasil ini konsisten dengan hasil penelitian Silitonga et al. (2018) yang melaporkan bahwa input luas lahan berpengaruh positif dan signifikan terhadap produksi padi. Hal ini memilik implikasi bahwa penambahan luas lahan perlu menjadi perhatian pemerintah jika hendak meningkatkan produksi padi lahan kering.

Input benih nyata berpengaruh terhadap produksi padi dengan elastisitas produksi frontier positif $(0,218)$. Artinya, tambahan jumlah benih sebanyak $1 \%$ akan mampu menaikkan produksi sebesar $0,218 \%$. Hal ini sesuai dengan hasil penelitian Nurjati et al. (2018) dimana benih secara nyata mempengaruh produksi padi. Pupuk $\mathrm{N}$ juga nyata memiliki pengaruh terhadap produksi pad dengan elastisitas produksi negatif. Artinya penambahan alokasi pupuk $\mathrm{N}$ justru akan menurunkan produksi padi. Kondisi ini disebabkan karena penggunaan pupuk N telah mencapai dosis yang berlebihan. Menurut Wahid (2003) penggunaan berlebihan dari pupuk $\mathrm{N}$ akan menjadi sebab menurunnya efisiensi pupuk dan juga berbahaya bagi tanaman serta lingkungan.

Pupuk $\mathrm{P}$ nyata berpengaruh terhadap produksi padi dengan elastisitas produksi frontier positif. Ini berarti penambahan pupuk $\mathrm{P}$ oleh petani akan mampu meningkatkan produksi padi. Hasil ini sesuai dengan temuan Kusnadi et al. (2011) yang menyatakan bahwa pupuk $\mathrm{P}$ berpengaruh nyata terhadap produksi padi di lima provinsi sentra produksi nasional. Pestisida padat juga nyata berpengaruh terhadap produksi padi namun dengan elastisitasnya bertanda negatif. Tanda koefisien yang negatif ini menunjukkan bahwa petani tidak menggunakan pestisida padat sesuai dosis yang diperlukan dan cenderung berlebihan. Faktor produksi tenaga kerja juga berpengaruh nyata. Elastisitas produksi sebesar 0,324 memiliki arti bahwa penambahan $1 \%$ tenaga kerja akan membuat produksi padi meningkat sebesar $0,324 \%$, dengan asumsi input lainnya tetap. Hasil ini mendukung penelitian Khakim et al. (2013) yang mengungkapkan bahwa tenaga kerja berperan sangat penting dalam usahatan padi untuk mengoptimalkan produksi.

Secara umum benih, pupuk, dan pestisida merupakan faktor produksi fisik yang selalu menempati pos biaya paling besar dalam usahatani padi (Kasmin \& Darsana, 2019). Dalam kondisi demikian, petani seharusnya lebih berhati-hati dalam mengalokasikan faktor produksi tersebut sehingga dapat lebih menghemat biaya produksi. Prinsip lima tepat harus diterapkan oleh petani dalam penggunaan pupuk dan pestisida, meliputi tepat jenis, tepat waktu, tepat dosis, tepat cara, dan tepat tempat. Hasil analisis juga menunjukkan input pupuk $\mathrm{K}$ dan pestisida cair tidak memiliki pengaruh yang nyata untuk produksi padi lahan kering.

\subsection{Efisiensi Teknis, Efisiensi Alokatif, dan Efisiensi Ekonomi}

Distribusi tingkat efisiensi teknis, efisiensi alokatif, dan efisiensi ekonomi petani padi lahan kering di Kabupaten Lampung Selatan ditampilkan dalam Tabel 2.

Rata-rata tingkat efisiensi teknis petani padi lahan kering di Kabupaten Lampung Selatan sebesar 0,869. Petani dengan tingkat efisiensi teknis tertinggi sebesar 0,991 dan terendah sebesar 0,634. Jumlah petani dengan nilai efisiensi teknis lebih dari 0,800 sebanyak 44 petani $(73,33 \%)$. Artinya hanya 16 petani $(26,67 \%)$ yang masih mengalami inefisiensi. Perbedaan dalam manajemen usahatani dan aplikasi teknologi menjadi penyebab perbedaan tingkat efisiensi diantara petani. Fauzan (2016) menyatakan bahwa faktor internal petani sepert umur, pengalaman, dan pendidikan serta faktor eksternal petani seperti penyuluhan menjadi sebab utama terjadinya perbedaan dalam manajemen usahatani dan aplikasi teknologi oleh petani.

Hasil analisis menunjukkan variabel umur, pengalaman, dan pendidikan petani nyata berpengaruh terhadap inefisiensi teknis usahatani padi lahan kering, sebagaimana ditunjukkan pada Tabel 3. Tanda positif pada ketiga variabel tersebut memiliki arti bahwa semakin tua umur petani, semakin lama pengalaman petani, dan semakin tinggi pendidikan formal petani maka tingkat inefisiensi juga semakin tinggi. Hasil ini sesuai dengan penelitian Cendrawasih et al. (2019), Sulistyaningsih \& Waluyati (2019), dan Husna et al. (2019). Hasil analisis juga menunjukkan rata-rata tingkat efisiensi alokatif yang dapat dicapai oleh petani padi lahan kering di Kabupaten Lampung Selatan adalah 0,957. Ini berarti mayoritas petani sudah efisien dalam mengalokasikan faktor-faktor produksi. Kondisi efisien secara alokatif merefleksikan kemampuan petani dalam menggunakan faktor-faktor produksi dalam proporsi yang optimal disesuaikan 
dengan kadar harganya masing-masing. Walaupun sudah cukup tinggi, tetap terbuka ruang bagi petani untuk meningkatkannya lagi.

Tabel 2. Distribusi Frekuensi Efisiensi Teknis, Alokatif, dan Ekonom

\begin{tabular}{lcccccc}
\hline \multirow{2}{*}{$\begin{array}{l}\text { Tingkat } \\
\text { Efisiensi }\end{array}$} & \multicolumn{2}{c}{ Efisiensi Teknis } & \multicolumn{2}{c}{ Efisiensi Alokatif } & \multicolumn{2}{c}{ Efisiensi Ekonomi } \\
\cline { 2 - 7 } & $\begin{array}{c}\text { Jumlah } \\
\text { Petani } \\
\text { (orang) }\end{array}$ & $\begin{array}{c}\text { Persentase } \\
(\%)\end{array}$ & $\begin{array}{c}\text { Jumlah } \\
\text { Petani } \\
\text { (orang) }\end{array}$ & $\begin{array}{c}\text { Persentase } \\
(\%)\end{array}$ & $\begin{array}{c}\text { Jumlah } \\
\text { Petani } \\
\text { (orang) }\end{array}$ & $\begin{array}{c}\text { Persentase } \\
(\%)\end{array}$ \\
\hline$<0,5$ & 0 & 0,00 & 0 & 0,00 & 0 & 0,00 \\
$0,51-0,60$ & 0 & 0,00 & 0 & 0,00 & 6 & 20,00 \\
$0,61-0,70$ & 2 & 3,33 & 3 & 5,00 & 5 & 8,33 \\
$0,71-0,80$ & 14 & 2,33 & 5 & 8,33 & 9 & 15,00 \\
$0,81-0,90$ & 15 & 25,00 & 8 & 13,33 & 18 & 30,00 \\
$0,91-1,00$ & 29 & 48,33 & 44 & 73,33 & 22 & 36,67 \\
Jumlah & 60 & & 60 & & 60 & \\
Rata-rata & 0,869 & & 0,957 & & 0,829 & \\
Nilai Minimum & 0,634 & & 0,616 & & 0,535 & 0,978 \\
Nilai Maksimum & 0,991 & & 1 & & & \\
\hline Sumber : Data primer diolah, 2019 & & & & &
\end{tabular}

Sumber : Data primer diolah, 2019

Tabel 3. Hasil Estimasi Faktor-Faktor yang Mempengaruhi Inefisiensi Teknis

\begin{tabular}{lccccc}
\hline \multicolumn{1}{c}{ Variabel } & Parameter & Koefisien & Standar error & t hitung \\
\hline Konstanta & $\delta_{0}$ & $-0,153$ & 0,161 & $-9,464$ & $* * *$ \\
Umur & $\delta_{1}$ & 0,224 & 0,493 & 4,551 & $* * *$ \\
Pengalaman & $\delta_{2}$ & 0,113 & 0,132 & 8,612 & $* * *$ \\
Pendidikan & $\delta_{3}$ & 0,223 & 0,992 & 2,255 & $* *$ \\
Kepemilikan lahan & $\delta_{4}$ & 0,147 & 0,125 & 1,169 & ns \\
Frekuensi & $\delta_{5}$ & $-0,905$ & 0,801 & $-1,126$ & ns \\
penyuluhan & & & & &
\end{tabular}

Sumber : Data primer diolah, 2019

$\begin{array}{lll}\text { Keterangan : } & * * * & : \text { signifikan untuk } \alpha=1 \% \\ & * * & : \text { signifikan untuk } \alpha=5 \% \\ & * & : \text { signifikan untuk } \alpha=10 \% \\ & \text { ns } & : \text { non-signifikan }\end{array}$

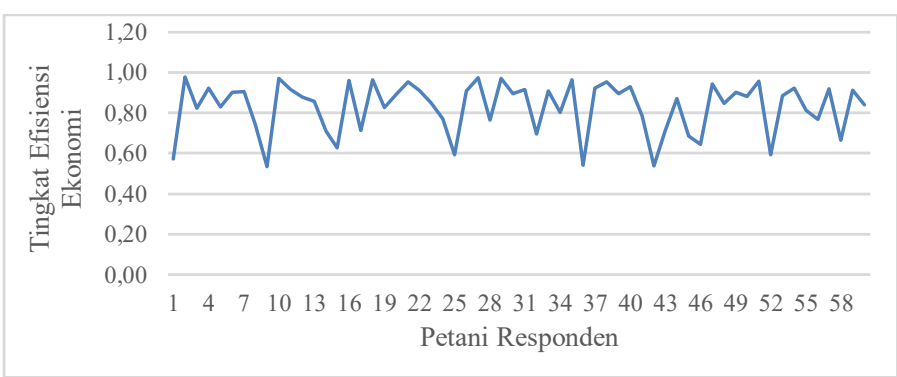

Gambar 1. Sebaran Tingkat Efisiensi Ekonomi

Efek kombinasi capaian efisiensi teknis dan alokatif petani padi lahan kering di Kabupaten Lampung Selatan menunjukkan capaian efisiensi ekonomi berada diantara 0,535 hingga 0,978 . Kelompok petani dengan tingkat efisiensi 0,91-1 memiliki presentase terbanyak sebesar 36,67\%. Jumlah terbanyak kedua berada pada nilai efisiensi 0,81 - 0,90 sebesar $30,00 \%$. Rata-rata capaian efisiensi ekonomi petani sebesar 0,829 dengan sebaran sebagaimana ditunjukkan oleh Gambar 1. Hasil analisis menunjukkan petani rata-rata dalam sampel akan mampu mencapai tingkat efisiensi ekonomi maksimum dengan menghemat biaya produksi sebesar $15,2 \%$ (1-[0,829/0,978]). Petani padi lahan kering yang paling inefisien pun akan mampu mencapai tingkat efisiensi ekonomi maksimum dengan menghemat biaya produksi sebesar 45,3\% (1-[0,535/0,978]).

Petani padi lahan kering di Kabupaten Lampung Selatan dapat meningkatkan efisiensi ekonominya dengan meningkatkan capaian efisiensi teknisnya. Hal ini dikarenakan capaian efisiensi alokatifnya sudah cukup tinggi (indeks efisiensi alokatif $>0,9$ ). Upaya yang dapat dilakukan oleh petani dalam rangka meningkatkan efisiensi teknis adalah dengan memperbaiki manajemen usahataninya (Kune et al. 2016) dengan meningkatkan kemampuan dalam aspek teknis budidaya dan adopsi inovasi teknologi baru yang lebih baik.

\section{Simpulan}

Faktor-faktor yang mempengaruhi produksi padi lahan kering di Kabupaten Lampung Selatan adalah luas lahan, benih, pupuk N, pupuk P pestisida padat, tenaga kerja, dan jenis benih. Rata-rata capaian efisiensi teknis, alokatif, dan ekonomi usahatani padi lahan kering di Kabupaten Lampung Selatan adalah sebesar 0,$869 ; 0,957$; dan 0,829 . Untuk mencapai tingkat efisien secara ekonomi, petani perlu meningkatkan capaian efisiensi teknis dan alokatifnya

\section{Pustaka}

Badan Pusat Statistik. (2004). Luas Lahan Menurut Penggunaannya di Indonesia. Jakarta. Badan Pusat Statistik.

Cendrawasih, R. R., Tinaprilla, N., \& Adhi, A. K. (2019). Technical Efficiency of Rice Farming with Jajar Legowo Planting System in Lamongan Regency, East Java Province. Jurnal Agro Ekonomi, 36(2), 149-162.
Fauzan, M. (2016). Pendapatan, Risiko, dan Efisiensi Ekonomi Usahatani Bawang Merah di Kabupaten Bantul. AGRARIS: Journal of Agribusiness and Rural Development Research, 2(2), 107-117.

Husna, H., Azis, Y., \& Fauzi, M. (2019). Analisis Efisiensi Teknis Usahatani Padi Sawah Pasang Surut Varietas Lokal di Kecamatan Barambai Kabupaten Barito Kuala. Frontier Agribisnis, 3(3).

Indah, L. S. M., Zakaria, W. A., \& Prasmatiwi, E. F. (2015). Analysis of Productions and Farming Income of Rice on Technical Irrigated Land and Raifed of South Lampung Regency. Jurnal Ilmu-Ilmu Agribisnis, 3 (3).

Irawan, B., \& Ariningsih, E. (2015). Dinamika Kebijakan dan Ketersediaan Lahan Pertanian. Pusat Sosial Ekonomi dan Kebijakan Pertanian. Kementrian Pertanian.

Jondrow, J., Lovell, C. K., Materov, I. S., \& Schmidt, P. (1982). On the estimation of technical inefficiency in the stochastic frontier production function model. Journal of Econometrics, 19(2-3), 233-238.

Kasmin, M., \& Darsana, N. (2019). Production Cost Efficiency of Rice Production of Subak and Non-Subak Groups in the Kolaka District. AGRIMOR, 4(4), 56-57.

Kay, R.D., W. M. Edwards, dan P. A. Duffy. (2008). Farm Management (Sixth Edition). McGraw-Hill International Edition. New York.

Khakim, L., Hastuti, D., \& Widiyani, A. (2013). Pengaruh Luas Lahan, Tenaga Kerja, Penggunaan Benih, dan Penggunaan Pupuk terhadap Produksi Padi di Jawa Tengah. Mediagro, 9(1), 71-79.

Kune, S., Muhaimin, A., \& Setiawan, B. (2016). Analisis Efisiensi Teknis dan Alokatif Usahatani Jagung (Studi Kasus di Desa Bitefa Kecamatan Miomafo Timur Kabupaten Timor Tengah Utara). AGRIMOR, 1(1), 3-6.

Kusnadi, N., Tinaprilla, N., Susilowati, S. H., \& Purwoto, A. (2011). Rice Farming Efficiency Analysis in Some Rice Producing Areas in Indonesia. Jurnal Agro Ekonomi, 29(1), 25-48.

Mulyani, A., Ritung, S., \& Las, I. (2011). Potential and Availability of Land Resources in Supporting Food Security in Indonesia. Jurnal Litbang Pertanian, 30(2), 73-80

Nalle, M. (2016). Analisis Efisiensi Sapi Potong di Kabupaten Kupang Provinsi Nusa Tenggara Timur. AGRIMOR, 1(3), 57-59.

Ningsih, K. (2011). Risiko Produksi dan Inefisiensi Teknis Usahatani Padi Gogo pada Agroekosistem Lahan Kering. AGROMIX, 2(1).

Nurjati, E., Fahmi, I., \& Jahroh, S. (2018). Analyzing the Efficiency of Shallot Production in Pati Regency Using the Cobb-Douglas Stochastic Frontier Production Function. Jurnal Agro Ekonomi, 36(1), 55-69.

Silitonga, P. Y., Hartoyo, S., Sinaga, B. M., \& Rusastra, I. W. (2018). Efficiency Analysis of Maize Farming on Dry Land trough Implementation of Integrated Crop Management in West Java Province. 25(2), 199-214.

Sulistyaningsih, Y. T., \& Waluyati, L. R. (2019). Technical Efficiency Analysis and Inefficiency Sources of Rice Farming in Narrow Lands in Bantul District Yogyakarta Province. Jurnal Pengkajian dan Pengembangan Teknologi Pertanian, 22(1), 27-38.

Wahid, A. S. (2003). Increasing Nitrogen Efficiency in Lowland Rice Using Leaf Color Chart Method. Jurnal Litbang Pertanian, 22(4), 156-161. 